\title{
Diabetic Foot in Algeria-The Debridement of Wounds-Our Attitude
}

\author{
Nadia Boudjenah* \\ Diabetic Foot Center, Algeria, Amara, Chéraga, Algeria \\ *Corresponding author: Nadia Boudjenah, Diabetic Foot Center, Algeria, Amara, Chéraga, Algeria \\ To Cite This Article: Nadia Boudjenah. Diabetic Foot in Algeria-The Debridement of Wounds-Our Attitude. Am J Biomed Sci \& Res. 2021 - 13(5). \\ AJBSR.MS.ID.001910. DOI: 10.34297/AJBSR.2021.13.001910.
}

Received: 筒 June 24, 2021; Published: 觜 July 30, 2021

\begin{abstract}
The management of the diabetic foot suffers or benefits from a plethora of methods and techniques. However, regardless of the therapeutic choice, one step is common: it is debridement. As a specialized center in the diabetic foot and its complications, we see very often, for their first visit to our outpatient's clinic, patients in care in other medical clinics/hospitals, and where the indication for amputation has already been made. Often, we find ourselves confronted with debrided wounds with irreversible damages hardly recoverable. Our understanding of debridement is straightforward and is based on clear, universally recognized definitions [1].
\end{abstract}

Keywords: Diabetic Foot; Plethora; Clinics/Hospitals; Wounds; Dead; Damaged; Surgical; Mechanical; Chemical; Autolytic; Healing; Blood Flow

\section{According to Wikipedia}

"Debridement is the medical removal of dead, damaged, or infected tissue to improve the healing potential of the remaining healthy tissue [2-3]. Removal may be surgical, mechanical, chemical, autolytic (self-digestion), and by maggot therapy". Debridement is an important part of the healing process.

\section{Surgical Debridement}

Surgical or "sharp" debridement and laser debridement under anesthesia are the fastest methods of debridement. They are very selective, meaning that the person performing the debridement has complete control over which tissue is removed and which is left behind [4]. Surgical debridement can be performed in the operating room or bedside, depending on the extent of the necrotic material and a patient's ability to tolerate the procedure. The surgeon will typically debride tissue back to viability, as determined by tissue appearance and the presence of blood flow in healthy tissue [5].

\section{Biological Debridement}

Maggot therapy is a form of biological debridement known since antiquity. The larvae of Lucilia sericata (greenbottle fly) are applied to the wound as these organisms can digest necrotic tissue and pathogenic bacteria. The method is rapid and selective, although patients are usually reluctant to submit to the procedure [6-11].

\section{According to Encyclopedia}

"Not all wounds need debridement". In such cases, the physician or nurse may decide not to debride the wound because blood flow may be insufficient for proper healing.

\section{Risks}

Structures may be damaged during the examination of the wound and during surgical debridement. Surface bacteria may also be introduced deeper into the body, causing infection. We set out our views on debridement through a series of cases identified in our center over the past six months, answering the following questions:
A. Is debridement mandatory?
B. What types of injuries is it aimed at?
C. when?
D. where? 

E. How?
F. And by whom should it be carried out?

\section{In summary, debridement is}

A. An integral part of the healing process.

B. It can be achieved only when the underlying blood flow is sufficient.

C. It is not mandatory for all lesions

D. It must be carried out by experienced professionals.

To illustrate our point, we will share iconographic files and develop our management of the diabetic foot, explorations, as well as our therapeutic strategy based on Carbomedtherapie (Carbon Dioxide Therapy-(https://www.sciforschenonline.org/journals/ endocrinology/IJEMD165.php). We will not discuss the importance of debridement, but when it should be done and the choice of technique. Debridement, due to the critical vascular condition in most of our patients, only worsens the lesions with aggravation of the necrosis in extent and depth, thus creating irreversible damages hardly recoverable. Exposing bone surfaces and tendons is the cause of non-healing, and therefore of amputations.

\section{Our attitude}

A. These are patients whose general condition is often altered, with an imbalance of defects and diabetes.

B. These patients arrive in a severely affected psychological state.

C. They are usually infected and with a defective circulatory condition.

D. They are so afraid of amputation that they don't eat, drink, or sleep anymore.

\section{Our priority is}

A. to rebalance defects, diabetes,

B. Perform antibiograms to effectively fight the infection.

C. To explore the macro and microcirculation using PERICAM* and PERIFLUX 6000*, and arterial and venous

\section{Echo Doppler}

We never use CT or MRI angiography. Their indications fall within the therapeutic vascular surgical possibility, which we do not have. In addition, we prefer non-invasive examinations. Restoring patient confidence is necessary. Without it, we won't be able to achieve compliance. We put the patient back in motion: physical activity, walking with complete discharge, and antioedema posture. The only emergency procedures are the emptying of abscesses with washing and drainage. We believe that necrosis is a "natural dressing" which must be observed before destroying it with Maggot Therapy treatment.

\section{Our Therapeutic}

A. local treatments consist of a water bath and H2O2, at 10 volumes, at a rate of three liters for 50cc (boiled then cooled water), followed by the application of LEADERMAX* (local ointment) and MAGGOT THERAPY daily until detachment or debridement.

B. At the same time, the patient benefits from sessions of Carbon Dioxide Therapy, anticoagulant, and antibiotic treatments.

C. After control by PERICAM*, surgical debridement is performed.

D. The maggots will have split the lesions into the area to be removed and the underlying budding due to the improved vascularity of the floor.

E. The relay is then taken by dressings with ALTRAZEAL* and BELCIC* cream.

F. Surgery may then be necessary to remove one or more toes or complete the neurectomy.

G. We usually cover the loss of substances with skin grafts, an action we no longer do routinely.

H. Arthrodesis regularly supplement this therapeutic arsenal.

\section{To debride}
A. Yes
B. Not at any time
C. By competent people
D. In good conditions

\section{Conclusion}

All these processes are carried out in our outpatient center. We had to develop simple techniques that were affordable to everyone because our patients have no reimbursement of any kind from the insurance companies or the government. In conclusion, to illustrate our previous remarks, we share a series of photos. We believe that visualizing real cases, allows to better assess the danger. Such anarchic gestures can lead to amputation or even death. A video, which was sent to me via Facebook, anonymous, is at the origin of this reflection. For young surgeons, it was seen as the example to follow (Figures). 

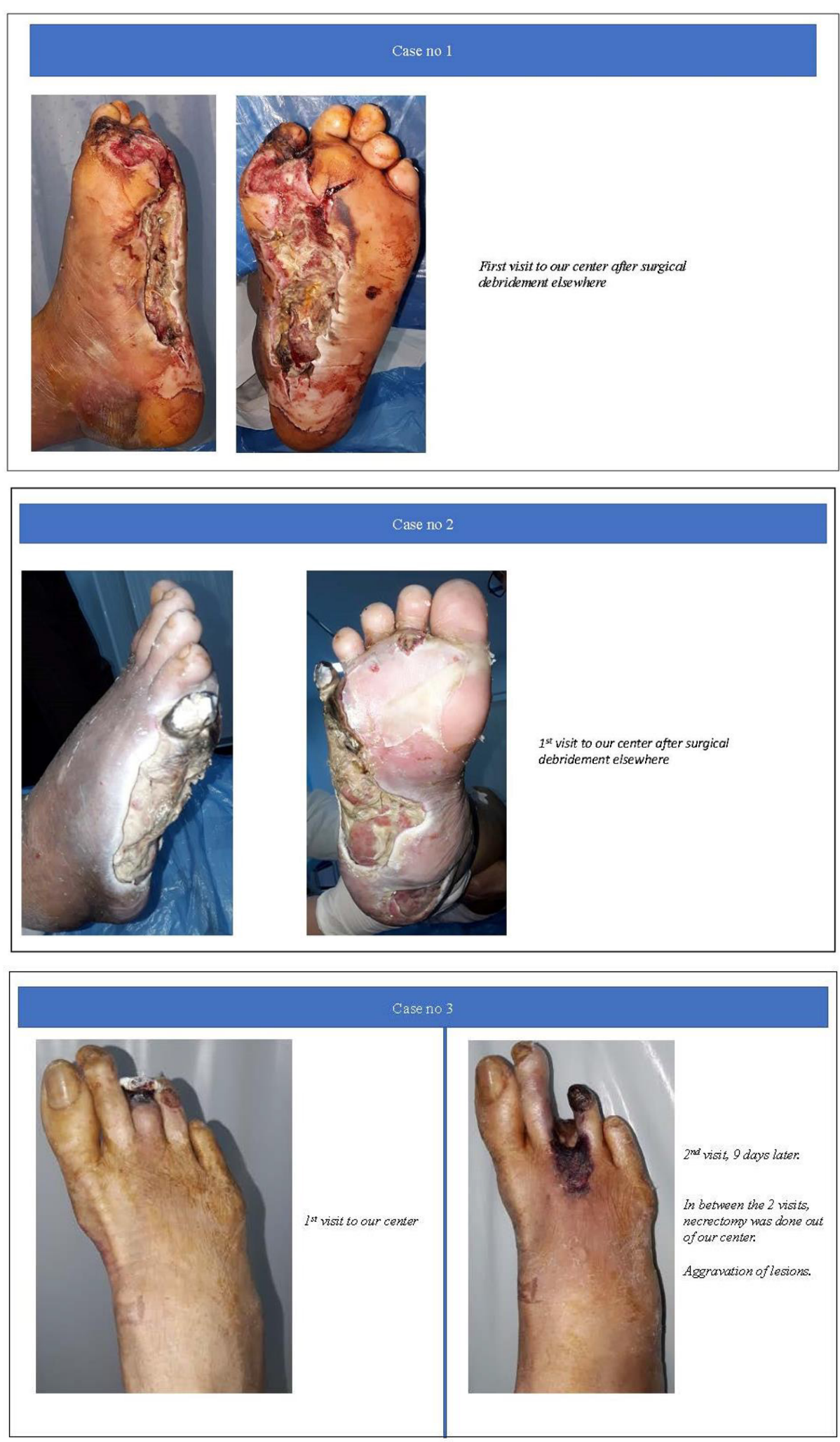

Figure. 

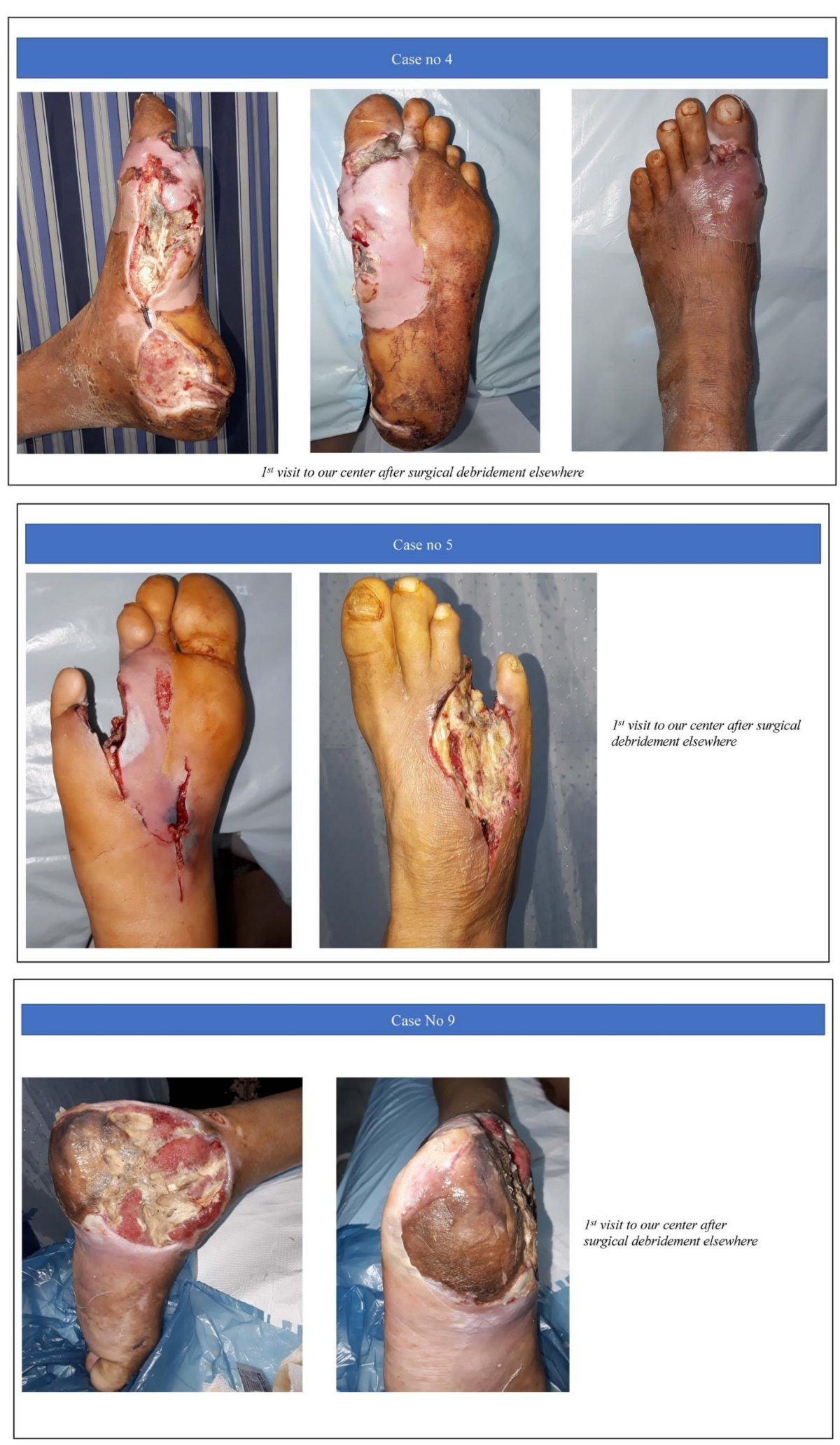

Figure. 

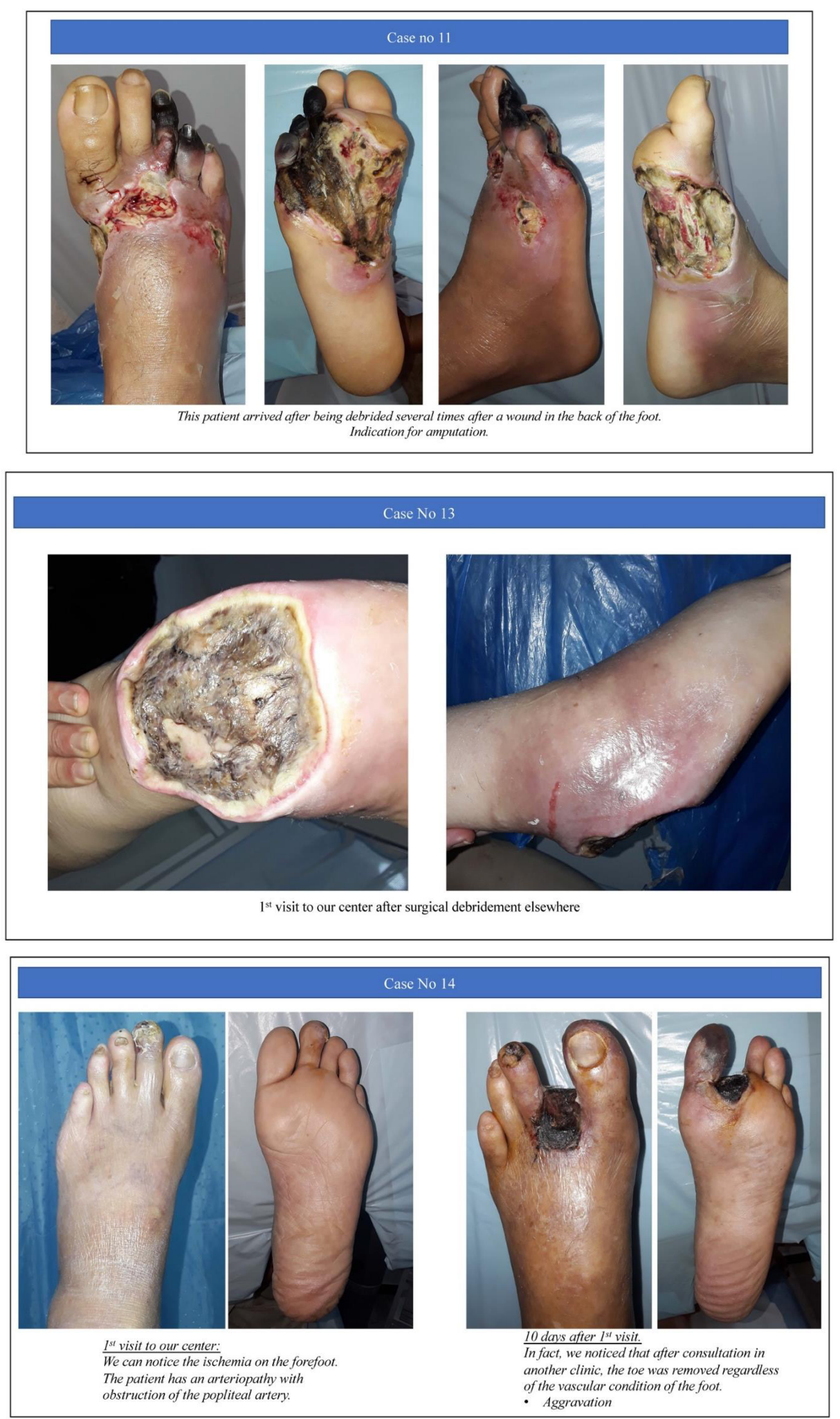

Figure. 
AFTER THERAPY TREATMENT WITH:

- CARBON DIOXIDE THERAPY (CDT)

- MAGGOT THERAPY, AND LEADERMAX CREAM

- ALTRAZEAL POWDER

- BELCIC CREAM

OUR RESULTS:
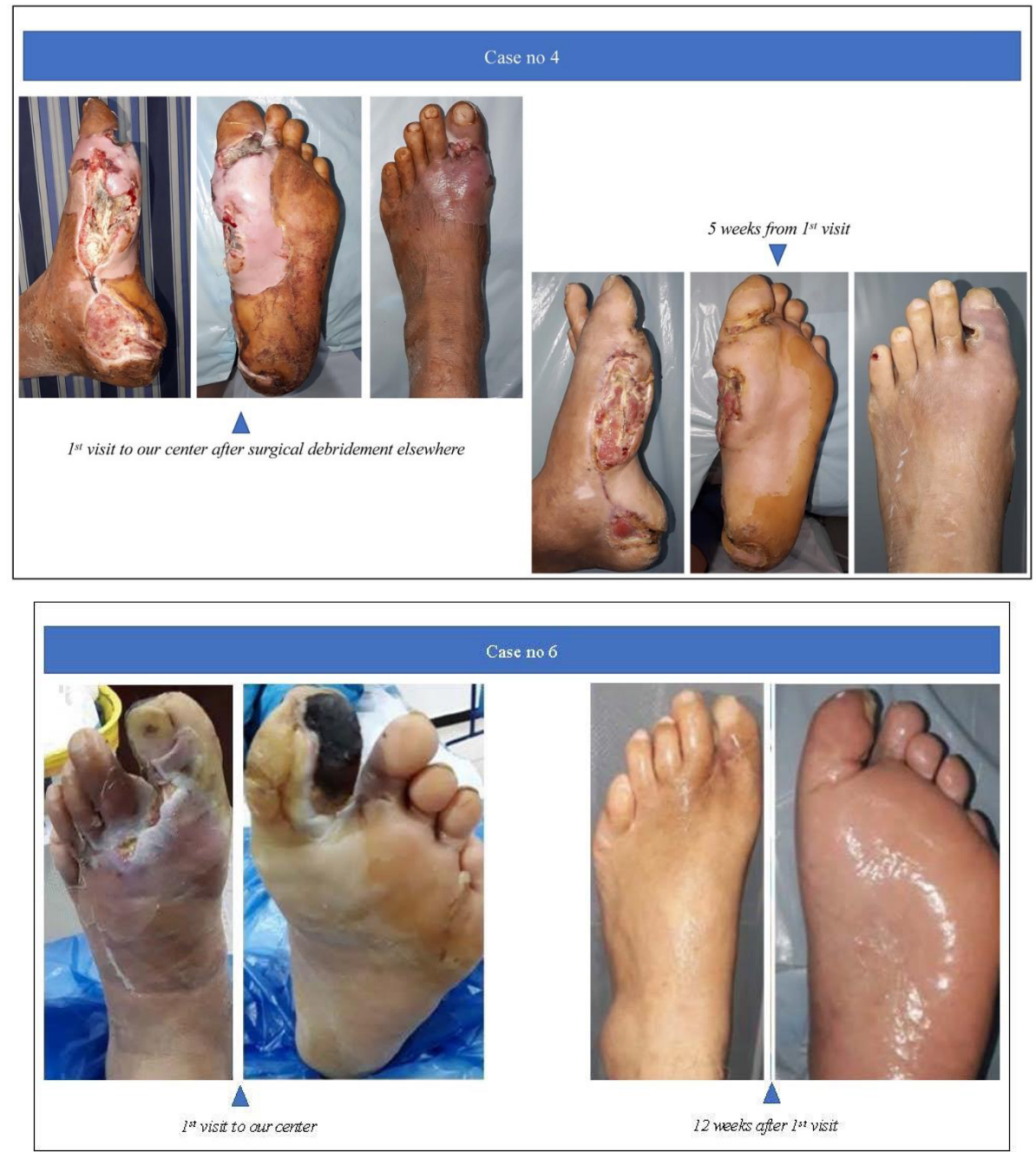

Figure. 


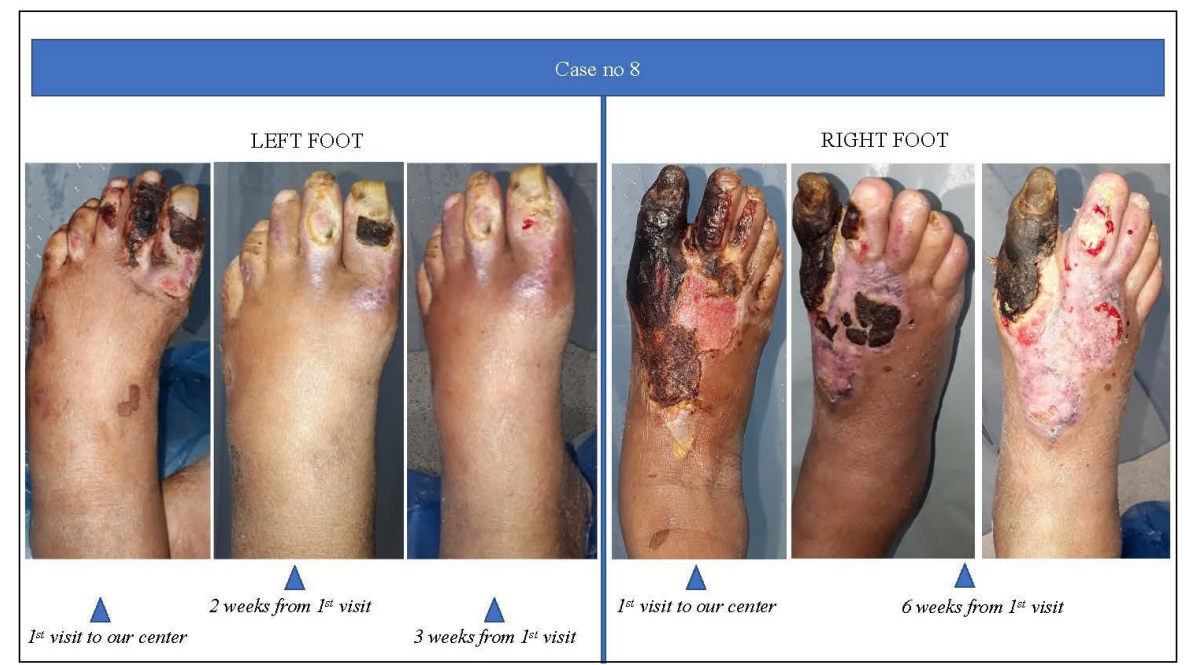

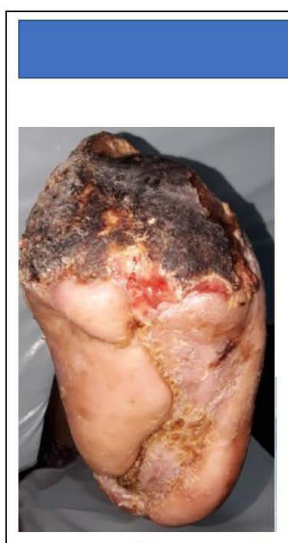

$\Delta$

$I^{\text {st }}$ visit to our center Necrosis post amputation

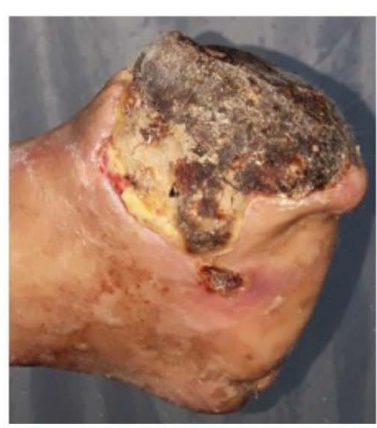

$\Delta$

4 weeks from $1^{15}$ visit
After Maggot Therapy treatment for the 4 weeks period, surgical debridement is performed
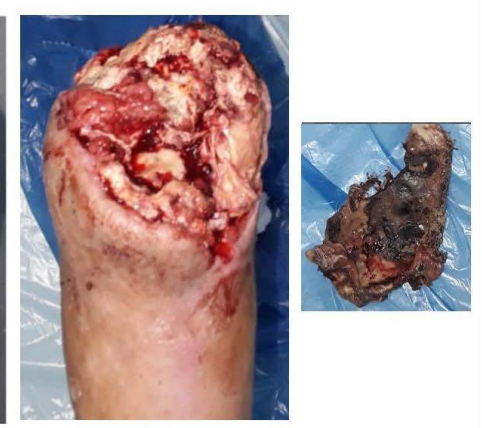
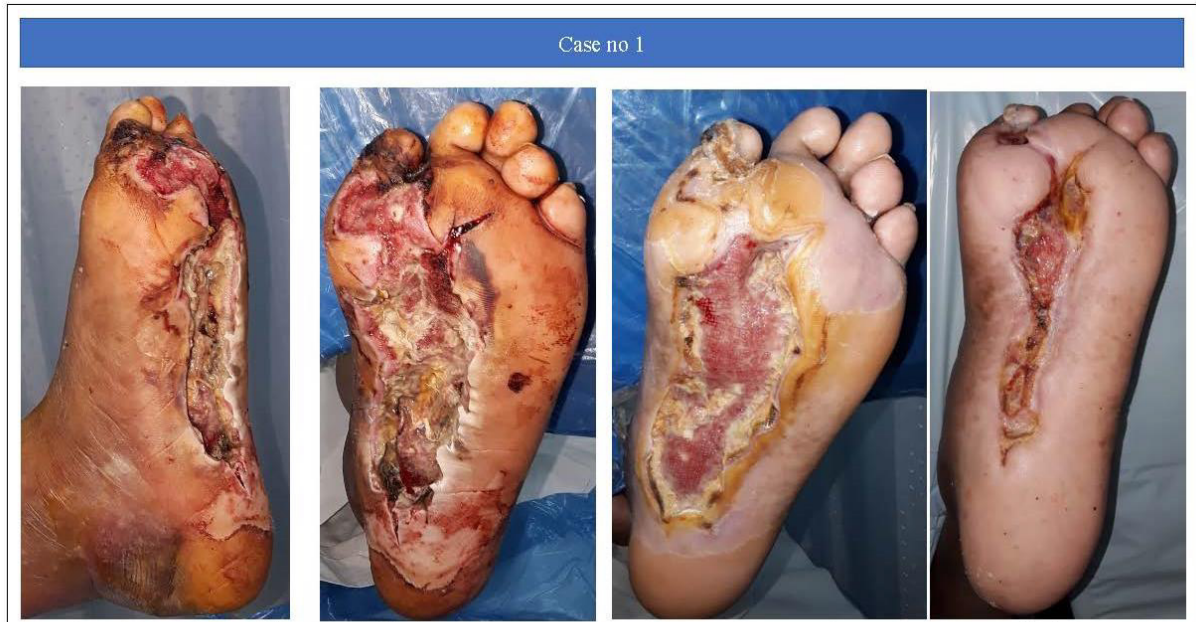

First visit to our center after surgical debridement else where

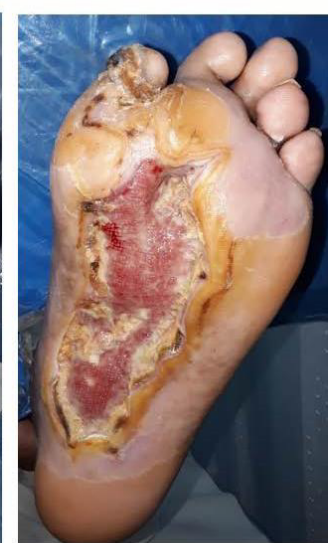

4 weeks from $1^{\text {st }}$ visit

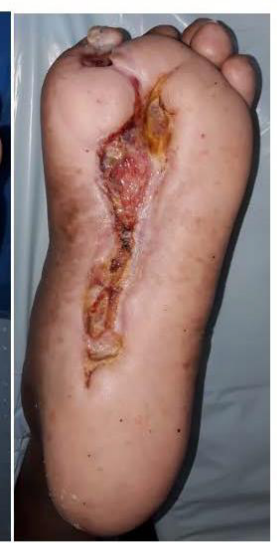

12 weeks from $1^{\text {st }}$ wisit

Figure. 

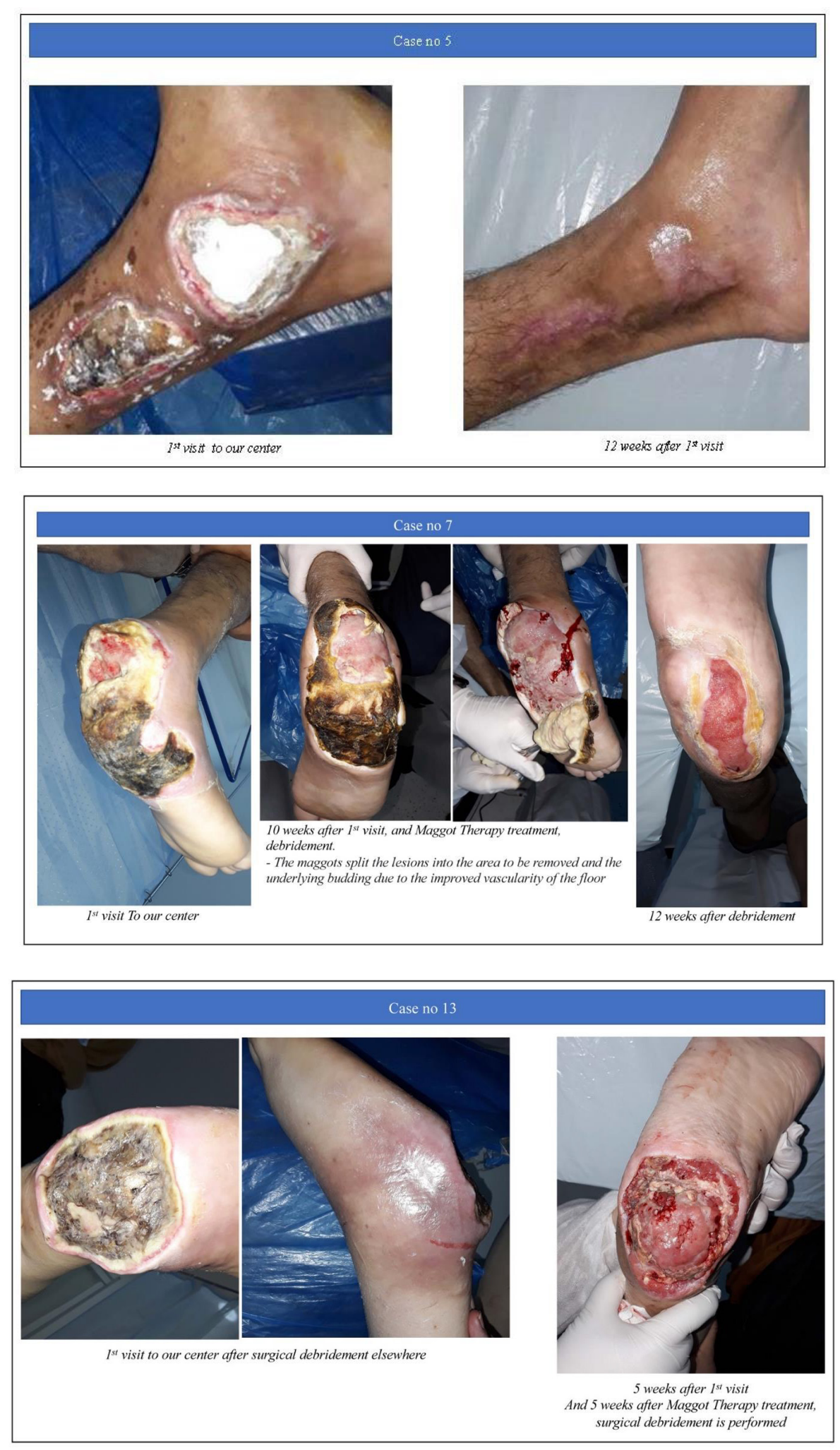

Figure. 

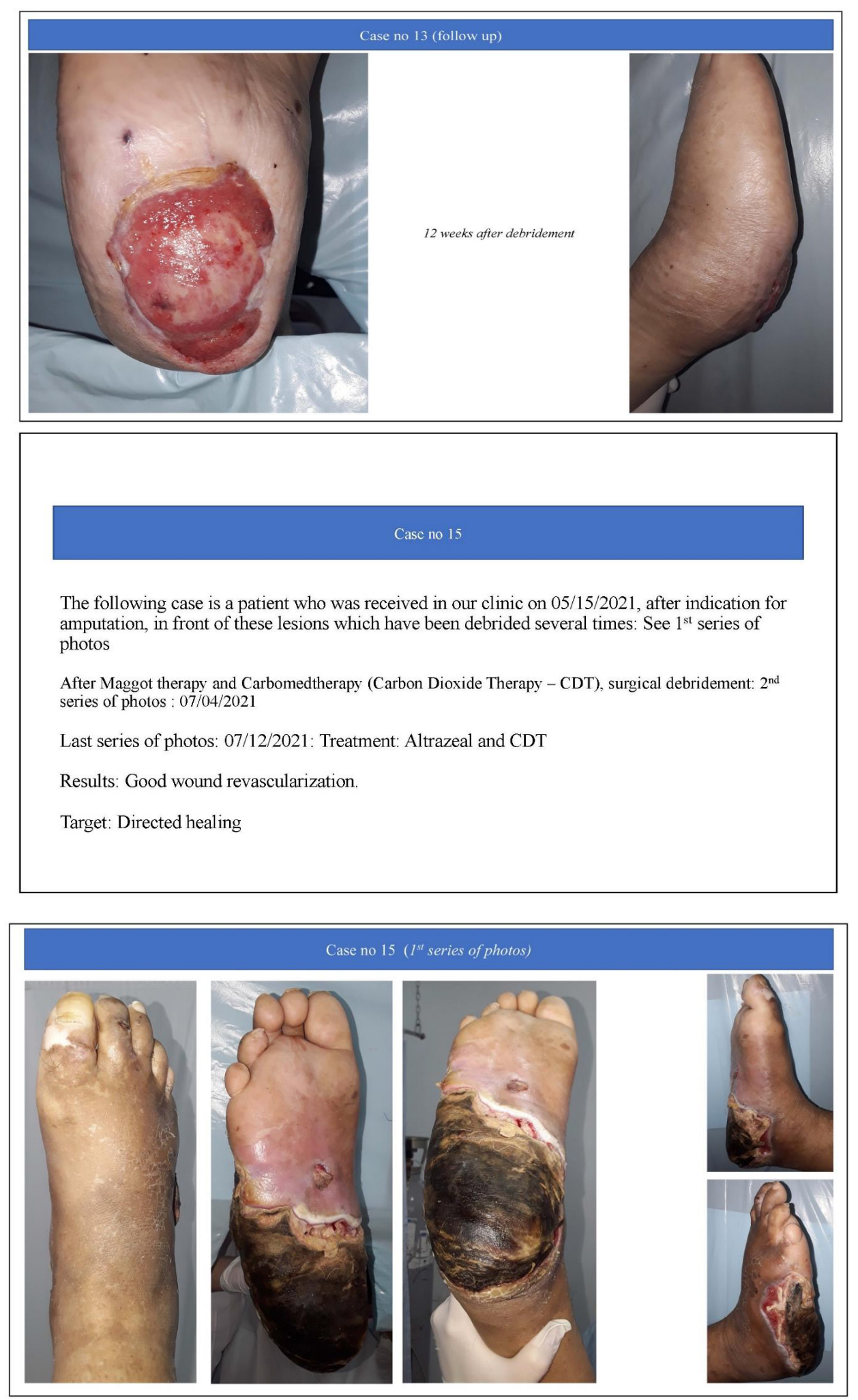

Figures. 

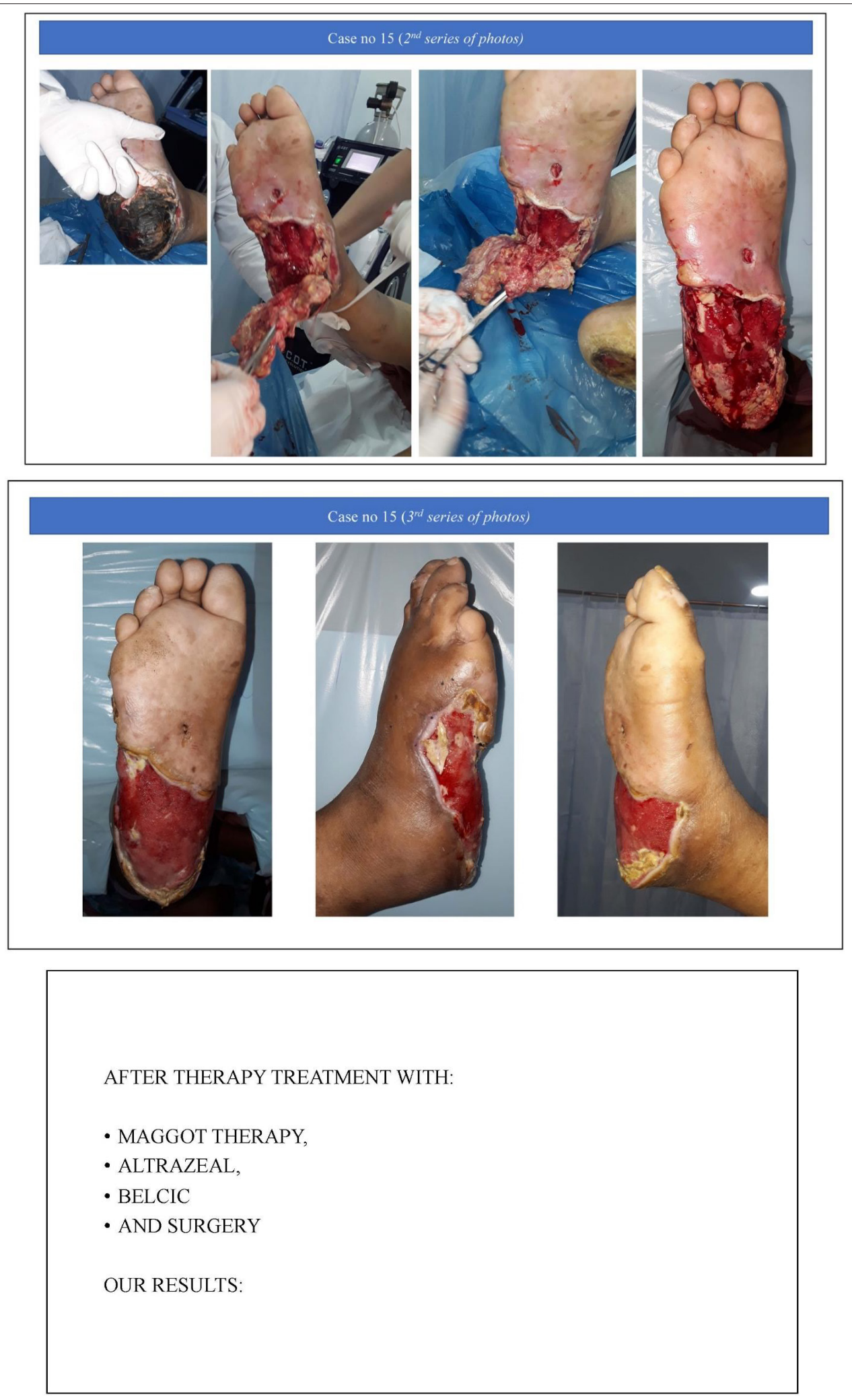

Figures. 

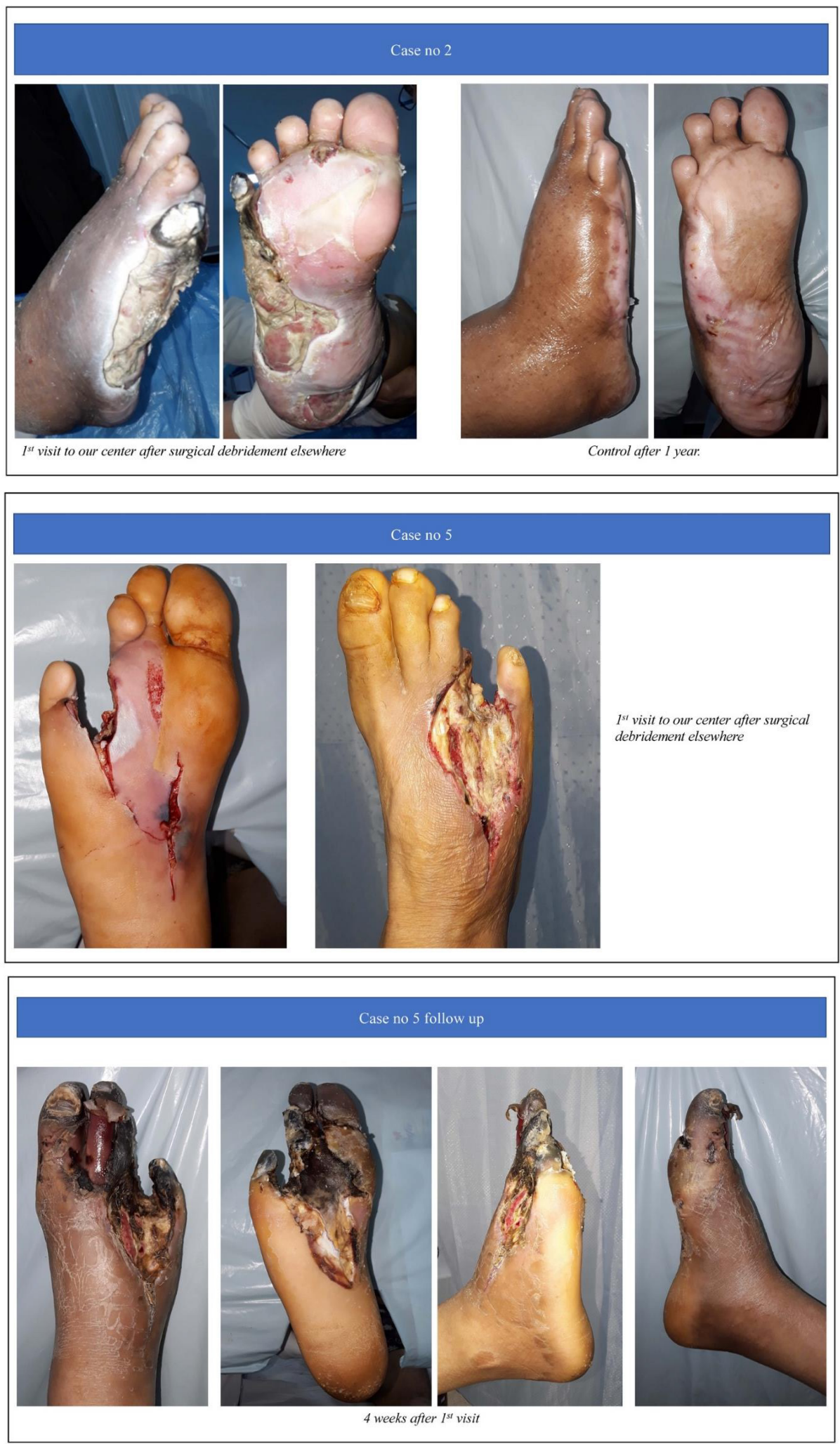

Figures. 

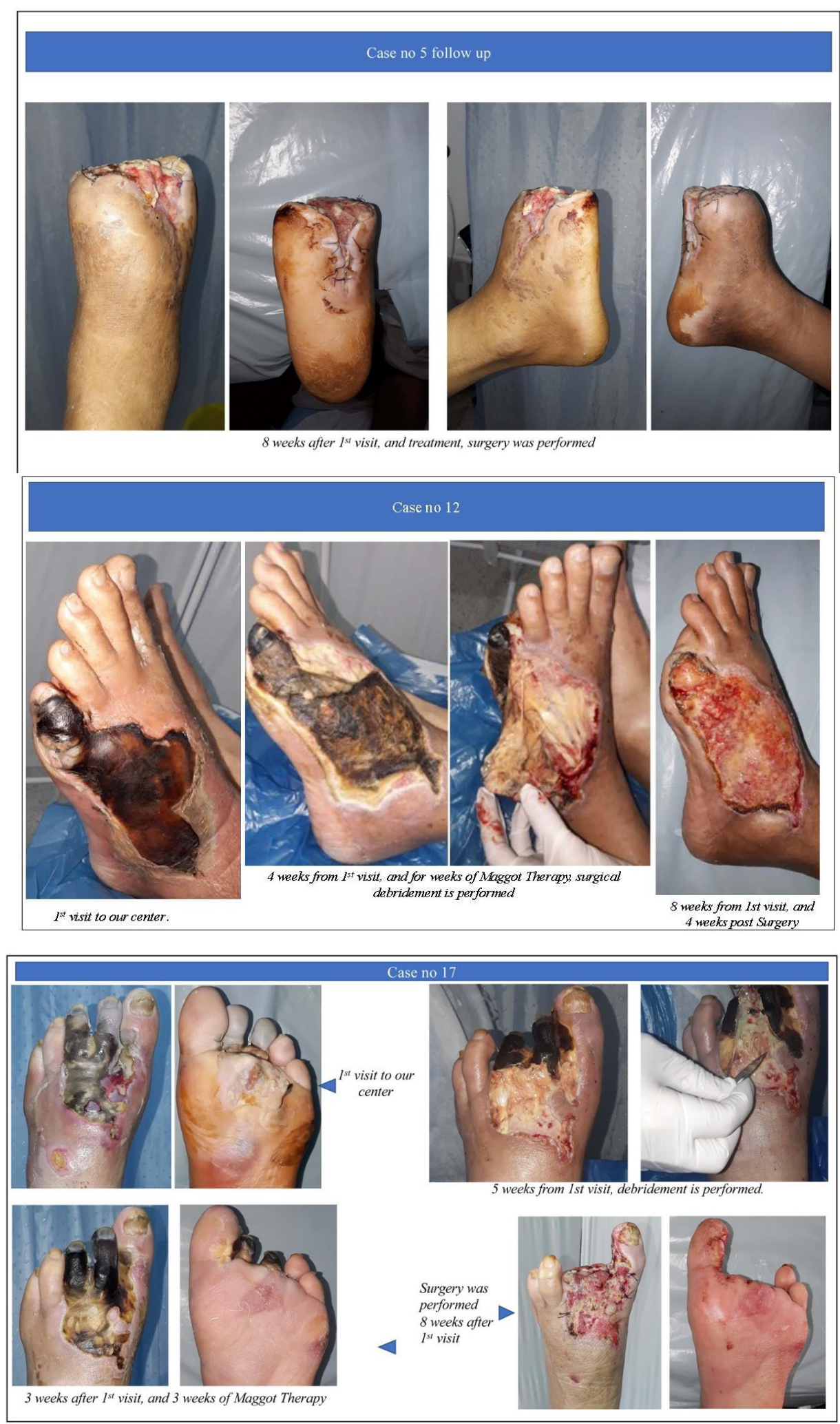

Figures. 


\section{Conflict of Interest}

No

\section{Interest in Any of The Equipment or Pharma- ceutical Products}

No

\section{References}

1. Martini RK, Sherman RA (2003) Maggot debridement therapy. J Bras Med 85: 82-85

2. Bexfield A, Nigam Y, Thomas S, Ratycliffe NA (2004) Detection, and partial characterization of two antibacterial factors from the excretions/ secretions of the medicinal maggot Lucilia sericata and their activity against methicillin-resistant Staphylococcus aureus (MRSA). Microbes Infect 6(14): 1297-1304

3. Marilia AR, Julianny B, Miguel AA, Andrew D, Maria ES (2006) Use of maggot therapy for treating diabetic foot ulcer colonized by multidrug resistant bacteria in Brazil. Indian J Med Res 141(3): 340-342.
4. Mclnnes W, RuzehajI N, Wright N, Cowin AJ, Fitridge R (2013) Venous laceration contaminated by multi resistant organisms: Larval therapy \& debridement. J Wound Care 22(S10): 27-30.

5. (2017) Diabetic Foot Conference abstracts.

6. Boudjenah N (2016) Diabetes and its Complications. Georgia World Congress Center. Atlanta USA.

7. Boudjenah N (2016) Introduction of Carbomedtherapy Endocrine Practice. Jacksonville 22: 16.

8. Boudjenah A (2013) Diabetic feet: contribution of Carbomedtherapy Diab Metab 39: A99.

9. Boudjenah N (2020) Diabetic Foot in Algeria. Int J Endocrinol Metab Disord 6.

10. Boudjenah N (2016) Introduction of Carbomedtherapy. Endocrine Practice. Pro Quest 22.

11. Advocacy for Carbomedtherapy in the treatment of Neuropathy. 